\title{
Treatment of Ruptured and Unruptured Intracranial Aneurysms with WEB 17 Versus WEB 21 Systems
}

\author{
Comparison of Indications and Early Angiographic Outcomes
}

I. König' $\cdot$ C. Maurer ${ }^{2}$ A. Berlis² $\cdot$ V. Maus ${ }^{1}$ W. Weber ${ }^{1} \cdot$ S. Fischer ${ }^{1}$

\begin{abstract}
Background The concept of intrasaccular flow diversion using the Woven EndoBridge (WEB) device changed the traditional endovascular concept for wide-necked bifurcation aneurysms. The latest technical advancement resulted in the WEB 17 system, a softer device composed of fewer wires which enables treatment of smaller more distally located aneurysms by using smaller microcatheters as compared to the WEB 21 system.

Objective This retrospective observational study aimed to evaluate and compare the angiographic and clinical results achieved with WEB 21 and WEB 17 in aneurysm morphologies eligible for both systems (maximum width 3-6 mm).

Methods Between August 2014 and August 2019 a total of 63 and 130 aneurysms with a maximum width of 3-6mm were treated with either WEB 21 and WEB 17, respectively, at 2 neurovascular centers. Cases were analyzed based on a comparison regarding aneurysm size, location and rupture status.

Results The technical success, the periprocedural complication rate and the rate of additional devices used showed no relevant differences between the two groups. Aneurysms treated with the WEB 17 system were smaller and more frequently distally located. The overall complete occlusion rate at 3 months was higher in the WEB 17 group (65.5\% versus 55.1\%). The superiority of complete aneurysm occlusion achieved with WEB 17 was statistically significant in the subgroup of unruptured middle cerebral artery aneurysms.

Conclusion The use of WEB 17 expands the treatment indications for intrasaccular flow-diversion towards smaller and more distally located aneurysms with a safety profile comparable with that of the WEB 21.
\end{abstract}

S. Fischer

sebif101@googlemail.com

1 Institut für Diagnostische und Interventionelle Radiologie, Neuroradiologie und Nuklearmedizin, Universitätsklinikum Knappschaftskrankenhaus Bochum-Langendreer, In der Schornau 23-25, 44892 Bochum, Germany

2 Klinik für Diagnostische und Interventionelle Radiologie und Neuroradiologie, Universitätsklinikum Augsburg, Stenglinstraße 2, 86156 Augsburg, Germany

$\begin{array}{ll}\text { Abbreviations } & \\ \text { ACA A2 } & \text { Anterior cerebral artery A2-segment } \\ \text { AcomA } & \text { Anterior communicating artery } \\ \text { SCA } & \text { Superior cerebellar artery } \\ \text { CT } & \text { Computed tomography } \\ \text { F } & \text { French } \\ \text { GCP } & \text { Good clinical practice } \\ \text { ICA } & \text { Internal carotid artery } \\ \text { MCA bif } & \text { Middle cerebral artery bifurcation } \\ \text { MCA M1 } & \text { Middle cerebral artery M1-segment } \\ \text { mRS } & \text { Modified Rankin scale } \\ \text { PCA P2 } & \text { posterior cerebral artery P2-segment } \\ \text { Pcom } & \text { Posterior communicating artery } \\ \text { PICA } & \text { Posterior inferior cerebellar artery }\end{array}$


SAH Subarachnoid hemorrhage

WEB Woven EndoBridge

\section{Introduction}

Intrasaccular flow disruption represents an innovative endovascular approach for wide-necked intracranial aneurysms. Experience with the WEB device (Woven EndoBridge, Microvention, Tustin, CA, USA) as the most established intrasaccular flow-disruptor is rapidly growing, while the device proved its effectiveness in several studies [1-4].

The concept of the WEB device was first described in 2011 [5]. A dense mesh of braided-nitinol wires disrupts the blood flow at the aneurysm neck.

While the first generations of WEB needed a 0.033 inch or 0.027 inch microcatheter, further technical developments facilitated a compatibility with a 0.021 inch microcatheter in 2015 for devices with a size range of $4-7 \mathrm{~mm}$. The latest version, the WEB 17 that is compatible with a 0.017 inch microcatheter, became available in 2017 with sizes ranging from $3-7 \mathrm{~mm}$ in width. The compatibility of WEB 17 with a 0.017 inch microcatheter becomes possible by a reduction of the total amount of wires that make up the device, while the metal coverage does not differ between both versions realized by a different braiding pattern in WEB 17 .

This was a comparative retrospective analysis of intracranial aneurysms treated with either WEB 21 or WEB 17 at two neurovascular centers. Aneurysm location, size, complication rates, immediate and 3 months follow-up angiographic results were analyzed separately.

Our hypothesis was that the angiographic success with WEB 17 is at least comparable to that of WEB 21 probably with a similar success and complication rate. Furthermore, we intended to investigate if WEB 17 expands the indications towards smaller and more distally located aneurysms.

\section{Material and Methods}

We performed a retrospective observational analysis of ruptured and unruptured intracranial aneurysms treated with WEB 21 and WEB 17 at two neurovascular centers between August 2014 and August 2019. Subgroups of this dataset were analyzed previously [6, 7].

There are different configurations of the WEB device available, a single layer (SL) more barrel-shaped configuration and a single layer sphere (SLS) configuration. The technical specifications were described before [5-8].

Our cohort included the time period before the introduction of WEB 17 at the participating centers in June 2017. Devices compatible with both a 0.017 inch and a 0.021 inch microcatheter were exclusively implanted with a 0.017 inch microcatheter. Since this was a retrospective evaluation inclusion and exclusion criteria were not prospectively defined. The analysis was restricted to aneurysms with a maximum width of 3-6 $\mathrm{mm}$ since these are potentially treatable with both systems (WEB 21 and WEB 17) in order to prevent biasing. Basic arguments in favor of treatment with the WEB were: an aneurysm size suitable for the given range of WEB devices, wide-necked morphology (dome to neck ratio $<2$ ), bifurcation type aneurysm.

\section{Procedure}

The treatment decision for unruptured aneurysms was made by a neurovascular board. The final decision for the specific endovascular strategy was made by the surgeon. Acutely ruptured cases were discussed by the responsible physicians.

All interventions were performed with the patient under general anesthesia on a biplane angiographic system (Siemens, Erlangen, Germany). Patients with unruptured aneurysms were placed on a dual antiplatelet medication at least 5 days prior to the procedure. This medication was only continued if necessary (e.g. additional placement of a stent). Ruptured aneurysms were treated without antiplatelet medication.

According to the manufacturer's sizing table aneurysms 2.0-6.5 $\mathrm{mm}$ in size are eligible for treatment with WEB 17 , whereas before the introduction of WEB 17 only aneurysms from $3.0-6.4 \mathrm{~mm}$ in width were suitable for WEB 21 (according to the " $+1 /-1$ rule" described below).

Sizing of the WEB was based on the " $+1 /-1$ rule" meaning an oversizing of $1 \mathrm{~mm}$ in width with a compensatory undersizing in height for WEB 21 as previously described in the literature [9]. Since the smaller devices with finer graduations of $0.5 \mathrm{~mm}$ in width for devices up to $5.0 \mathrm{~mm}$ need a lower amount of oversizing and undersizing the "+1/-1 rule" becomes incorrect. Therefore, the sizing table provided by the manufacturer indicates the correct size depending on aneurysm measurements in two orthogonal projections for WEB 17 [7, 8].

Following the selection of the WEB device an appropriate microcatheter (VIA 21 or VIA 17, Microvention) was advanced towards the aneurysm in a projection without superimposition of the surrounding vessels. The WEB was pushed towards the aneurysm while the forces transferred to the microcatheter arising from the pusher wire of the device were balanced to keep the microcatheter stable. The device was deployed within the aneurysm and finally detached after an observational period of $10 \mathrm{~min}$ as described before [6-9]. Additional devices, such as self-expanding stents to stabilize the WEB device or coils to completely occlude the aneurysm were applied based on the individual decision of the interventionalist. 


\section{Follow-up Schedule}

Angiographic and clinical follow-up examinations were scheduled at 3 and 12 months. Follow-up examinations were carried out as conventional digital subtraction angiography (DSA) according to the institutional standards, while in exceptional cases magnetic resonance (MR) angiography was performed. Clinical results were graded according to the modified Rankin scale (mRS).

\section{Data Collection}

Clinical and angiographic characteristics including procedural specifics were entered in a previously adapted database.

Complications were analyzed according to their time of appearance as periinterventional or postinterventional. Furthermore, complications were classified as clinically relevant in cases of transient or permanent neurological deterioration.

The clinical status of each patient was determined by the $\mathrm{mRS}$ on admission, at discharge and at the follow-up visits.

Angiographic results were classified according to the 3-point scale of Roy and Raymond modified to the special characteristics of intrasaccular flow diversion as described by Caroff et al. as follows: complete occlusion (grade 1), opacification of the proximal recess of the WEB device or neck remnant (grade 2), aneurysm remnant or residual flow inside the WEB device (grade 3 ) $[4,10]$.

\section{Statistical Analysis}

Statistical analysis was performed by using Microsoft Excel. Continuous variables are given as the median and range. Categorical variables are reported in absolute numbers and percentages. To test normal distribution of continuous variables we used the Shapiro-Wilk test. The t-test and MannWhitney U-test were used for group comparisons. For comparison of frequency distribution of categorical variables in independent groups Fisher's exact test was used. A $p$-value $<0.05$ was considered statistically significant.

\section{Ethical Statement}

This retrospective study obtained approval by the local ethics committee and was performed in accordance with the ethical standards laid down in the 1964 Declaration of Helsinki and its later amendments. A separate informed consent was not required due to the retrospective design of this study.

\section{Results}

\section{Descriptive Data}

Between August 2014 and August 2019 a total of 215 aneurysms were treated with the WEB 21 (70 aneurysms) and WEB 17 system (145 aneurysms). Of these 193 aneurysms met the above described inclusion criterion of a maximum width between 3 and $6 \mathrm{~mm}$. These were included into the further analysis. Of the 193 aneurysms 63 (62 patients) were treated with WEB 21 and 130 (122 patients) were treated using the WEB 17 system.

There were 22 and 29 acutely ruptured aneurysms in the WEB 21 and the WEB 17 group, respectively and 3 (WEB 21) and 6 (WEB 17) aneurysms were remnants (clipping or coiling).

The rate of incidental aneurysms in both groups was $60.3 \%$ (38/63 aneurysms) in the WEB 21 and $73.1 \%$ (95/130 aneurysms) in the WEB 17 group.

Table 1 Patient and aneurysm characteristics in WEB 21 and the WEB 17 treated aneurysms (AcomA anterior communicating artery, $M C A$ bif middle cerebral artery bifurcation, $M C A M 1$ middle cerebral artery bifurcation M1-segment, ICA terminus internal carotid artery terminus, ICA Pcom posterior communicating artery, ACA A2 anterior cerebral artery A2 segment, $S C A$ superior cerebellar artery, $P C A$ $P 2$ posterior cerebral artery $\mathrm{P} 2$ segment, $P I C A$ posterior inferior cerebellar artery)

\begin{tabular}{|c|c|c|}
\hline Characteristics & WEB 17 & WEB 21 \\
\hline Aneurysms (n) & 130 & 63 \\
\hline Successful WEB implantation $(n)$ & 128 & 60 \\
\hline Patients $(n)$ & 122 & 62 \\
\hline Patient age (years) & $57.5 \pm 11.9$ & $58.2 \pm 13.2$ \\
\hline Ruptured aneurysms (n) & $29(22.3 \%)$ & $22(34.9 \%)$ \\
\hline \multicolumn{3}{|l|}{ Location of aneurysm } \\
\hline Anterior circulation $(n)$ & $116(89.2 \%)$ & $54(85.7 \%)$ \\
\hline $\operatorname{AcomA}(n)$ & $36(31.0 \%)$ & $16(29.6 \%)$ \\
\hline $\operatorname{MCA}$ bif $(n)$ & $55(47.4 \%)$ & $29(53.7 \%)$ \\
\hline MCA M1 (n) & $1(0.9 \%)$ & - \\
\hline ICA terminus $(n)$ & $6(5.2 \%)$ & $6(11.1 \%)$ \\
\hline $\operatorname{ICA} \operatorname{Pcom}(n)$ & $11(9.5 \%)$ & $3(5.6 \%)$ \\
\hline ACA A2 $(n)$ & $7(6.0 \%)$ & - \\
\hline Posterior circulation $(n)$ & $14(10.8 \%)$ & $9(12.9 \%)$ \\
\hline Basilar tip (n) & $8(57.1 \%)$ & $7(77.8 \%)$ \\
\hline $\operatorname{SCA}(n)$ & $3(21.4 \%)$ & $2(22.2 \%)$ \\
\hline PCA P2 $(n)$ & $1(7.1 \%)$ & - \\
\hline $\operatorname{PICA}(n)$ & $2(14.3 \%)$ & - \\
\hline \multicolumn{3}{|l|}{ Aneurysm size } \\
\hline$\leq 4.9 \mathrm{~mm}$ width & $84(64.6 \%)$ & $27(42.9 \%)$ \\
\hline$\geq 5.0 \mathrm{~mm}$ width & $46(35.4 \%)$ & $36(57.1 \%)$ \\
\hline Aneurysm width (mm) & $4.2 \pm 1.0$ & $4.7 \pm 0.9$ \\
\hline Aneurysms height (mm) & $4.7 \pm 1.3$ & $5.2 \pm 1.4$ \\
\hline Neck width (mm) & $3.0 \pm 0.9$ & $4.0 \pm 0.7$ \\
\hline Aspect ratio & $1.6 \pm 0.5$ & $1.3 \pm 0.4$ \\
\hline
\end{tabular}


Baseline patient and aneurysm characteristics are summarized in Table 1.

\section{Main results}

Treatment with WEB 21 and WEB 17 was successful in $60 / 63(95.2 \%)$ and in 128/130 (98.5\%) cases, respectively. Cases of failed treatment with WEB were excluded from further analysis concerning follow-up results but were included in the analysis of complications.

Self-expanding stents were used in 2/60 (3.3\%) WEB 21 and $13 / 128(10.2 \%)$ WEB 17 cases in order to stabilize the WEB device and to preserve the parent artery. While in seven cases in the WEB 17 group the combination with a self-expanding stent was part of the planned treatment strategy, the remaining cases of both groups were the result of an individual decision by the surgeon after placement of the selected WEB device. In these cases, the stent was placed due to an unexpected extension of the WEB device into the parent artery. The stents used in these cases were Neuroform Atlas (Stryker, Kalamazoo, MI, USA) or LVIS (Microvention).

In $2 / 60(3.3 \%)$ cases of the WEB 21 and in 4/128 (3.2\%) of the cases in the WEB 17 group coils were placed in addition to the WEB device. As described this was done at the surgeon's discretion in cases of irregular shaped aneurysms with larger daughter aneurysms.

We observed thromboembolic complications in 4 of the $63(6.3 \%)$ cases in the WEB 21 and in 7 of the $130(5.4 \%)$ cases in the WEB 17 group and 1 hemorrhagic complication occurred in the WEB 17 group (0.8\%). Complications during the follow-up period were not observed.

Of the four thromboembolic complications within the WEB 21 group one was an acute occlusion of the MCA after placement of a LVIS stent in order to stabilize the WEB device inside the MCA aneurysm that was treated by intraarterial admission of $20 \mathrm{ml}$ alteplase (Actilyse, Boehringer Ingelheim, Germany). This patient developed a paresis of the left arm (mRS 3). In another case of a previously ruptured ICA $P$ com artery aneurysm, an acute occlusion of the ICA was treated by intra-arterial insertion of tirofiban and mechanical thrombectomy and the final placement of a Neuroform Atlas stent. This patient died 2 days after the procedure due to a complete infarction of the MCA territory. In the other two cases of unruptured MCA bifurcation aneurysms a thrombus formation within the parent artery resolved spontaneously after repositioning of the WEB device and in the second case the MRI performed 1 day after the procedure revealed an ischemic lesion within the MCA territory without periinterventional angiographic evidence of a thrombus formation. This patient experienced an increase in the pre-existing hemiparesis ( $\mathrm{mRS} 2$ ), while the other patient remained asymptomatic.
Of the seven thromboembolic complications in the WEB 17 group three cases of thrombus formation within the parent artery were successfully treated by an intravenous bolus of aspisol $(500 \mathrm{mg})$ or intravenous administration of eptifibatide. In one case of an incidental MCA bifurcation aneurysm the thrombus formation within the MCA showed a spontaneous regression. In another case of a MCA bifurcation aneurysm the bottom of the WEB device extended into the superior trunk of the MCA. This position resulted in a thrombus formation within the parent artery that was successfully treated with a Neuroform Atlas stent. The patient remained without clinical symptoms.

In two cases of MCA bifurcation aneurysms (one acutely ruptured and the other incidental) the WEB device dislocated during the detachment, which resulted in a permanent occlusion of the superior trunk of the MCA in one case, while in the other the occlusion was successfully treated by mechanical thrombectomy and a Neuroform Atlas stent. The patient with the ruptured MCA aneurysm died probably related to the pre-existing subarachnoid hemorrhage (SAH) but nevertheless this complication was classified as clinically relevant, while the other experienced a mild clinical deterioration (mRS 2).

There was one case of periprocedural SAH without extravasation of blood observed during the procedure but an increasing $\mathrm{SAH}$ on the postinterventional CT. This was a case within the WEB 17 group of a previously ruptured aneurysm of the MCA bifurcation resulting in a permanent lack of concentration and a chronic fatigue (mRS 1).

Seven patients in the WEB 21 and 5 patients in the WEB 17 group died as the consequence of the SAH already existing on admission.

The procedure-related morbidity and mortality rates in the entire series were $3.2 \%$ (2/62 patients) and $1.6 \%$ (1/62 patients) in the WEB 21 group and $2.5 \%(3 / 122$ patients) and $0.0 \%$ in the WEB 17 group, respectively.

Immediate complete occlusion documented on the final run was observed in 7/60 (11.7\%) and 19/128 (14.8\%) cases within the 2 groups (WEB 21 and WEB 17), respectively.

To date, $49 / 60(81.7 \%)$ and $84 / 128(65.6 \%)$ of the aneurysms were followed up at least once at 3 months in both groups (WEB 21 and WEB 17) with a range of

Table 2 Angiographic results at 3 months for WEB 21 and WEB 17 treated aneurysms. Overall comparison, grade 1: complete occlusion; grade 2: opacification of the proximal recess of the WEB device or neck remnant; grade 3: aneurysm remnant or residual flow inside the WEB device

\begin{tabular}{lll}
\hline 3-month follow-up & WEB 21 & WEB 17 \\
\hline$N$ & $81.7 \%(49 / 60)$ & $65.6 \%(84 / 128)$ \\
Grade 1 & $55.1 \%(27 / 49)$ & $65.5 \%(55 / 84)$ \\
Grade 2 & $36.7 \%(18 / 49)$ & $21.4 \%(18 / 84)$ \\
Grade 3 & $8.2 \%(4 / 49)$ & $13.1 \%(11 / 84)$ \\
\hline
\end{tabular}


1-20 months. The complete occlusion rate progressed to $55.1 \%$ (27/49 aneurysms) and 65.5\% (55/84 aneurysms) in the WEB 21 and the WEB 17 groups. The higher complete occlusion at 3 months was not statistically significant $(p=0.119)$.

Table 2 summarizes the occlusion rates in the WEB 21 and the WEB 17 group at 3 months.

\section{Subgroup Analysis}

We performed an additional subgroup analysis of unruptured aneurysms of the MCA as the most common location in both groups in order to minimize potential confounding factors.

There were 21 (WEB 21) and 41 (WEB 17) aneurysms in this subgroup. To date, 21/21 (100.0\%) and 30/41 (73.2\%) of all aneurysms in this subgroup were followed-up at least once at 3 months.

The size distribution within the given range of $3.0-6.0 \mathrm{~mm}$ was different with smaller aneurysms in WEB 17 group (Table 3).

Aneurysms treated with WEB 17 showed significantly higher rates of complete occlusion in this subgroup analysis $(p=0.04)$. Complete occlusion at 3 months was $57.1 \%$

Table 3 Size distribution in the subgroup analysis of unruptured middle cerebral artery bifurcation aneurysms from $3.0-6.0 \mathrm{~mm}$ in width treated with WEB 21 or WEB 17

\begin{tabular}{lll}
\hline Width & WEB 21 & WEB 17 \\
\hline$N$ & $100.0 \%(21 / 21)$ & $100 \%(41 / 41)$ \\
$3 \mathrm{~mm}$ & $19.0 \%(4 / 21)$ & $24.4 \%(10 / 41)$ \\
$4 \mathrm{~mm}$ & $28.6 \%(6 / 21)$ & $43.9 \%(18 / 41)$ \\
$5 \mathrm{~mm}$ & $38.1 \%(8 / 21)$ & $17.1 \%(7 / 41)$ \\
$6 \mathrm{~mm}$ & $14.3 \%(3 / 21)$ & $14.6 \%(6 / 41)$ \\
\hline
\end{tabular}

Table 4 Comparison of middle cerebral artery bifurcation aneurysms from 3.0-6.0 mm in width treated with WEB 21 and WEB 17. Angiographic results at 3 months follow-up (grade 1: complete occlusion; grade 2: opacification of the proximal recess of the WEB device or neck remnant; grade 3: aneurysm remnant or residual flow inside the WEB device)

\begin{tabular}{lll}
\hline 3-month follow-up & WEB 21 & WEB 17 \\
\hline$N$ & $100.0 \%(21 / 21)$ & $73.2 \%(30 / 41)$ \\
Grade 1 & $57.1 \%(12 / 21)$ & $70.0 \%(21 / 41)$ \\
Grade 2 & $38.1 \%(8 / 21)$ & $10.0 \%(3 / 41)$ \\
Grade 3 & $4.8 \%(1 / 21)$ & $20.0 \%(6 / 41)$ \\
\hline
\end{tabular}

Fig. 1 a Incidental finding of a broad-based MCA bifurcation aneurysm in a 52-year-old patient; posterior-anterior view caudal angulation. b three dimensional rotational angiography of the MCA bifurcation aneurysm. c placement of a WEB 17 SL $4.5 \times 3 \mathrm{~mm}$ device with correct reconstruction of the aneurysm neck before detachment; posteroanterior view caudal angulation. d 3-month follow-up angiography with complete occlusion of the MCA bifurcation aneurysm and unchanged flow within the parent arteries; posteroanterior view caudal angulation
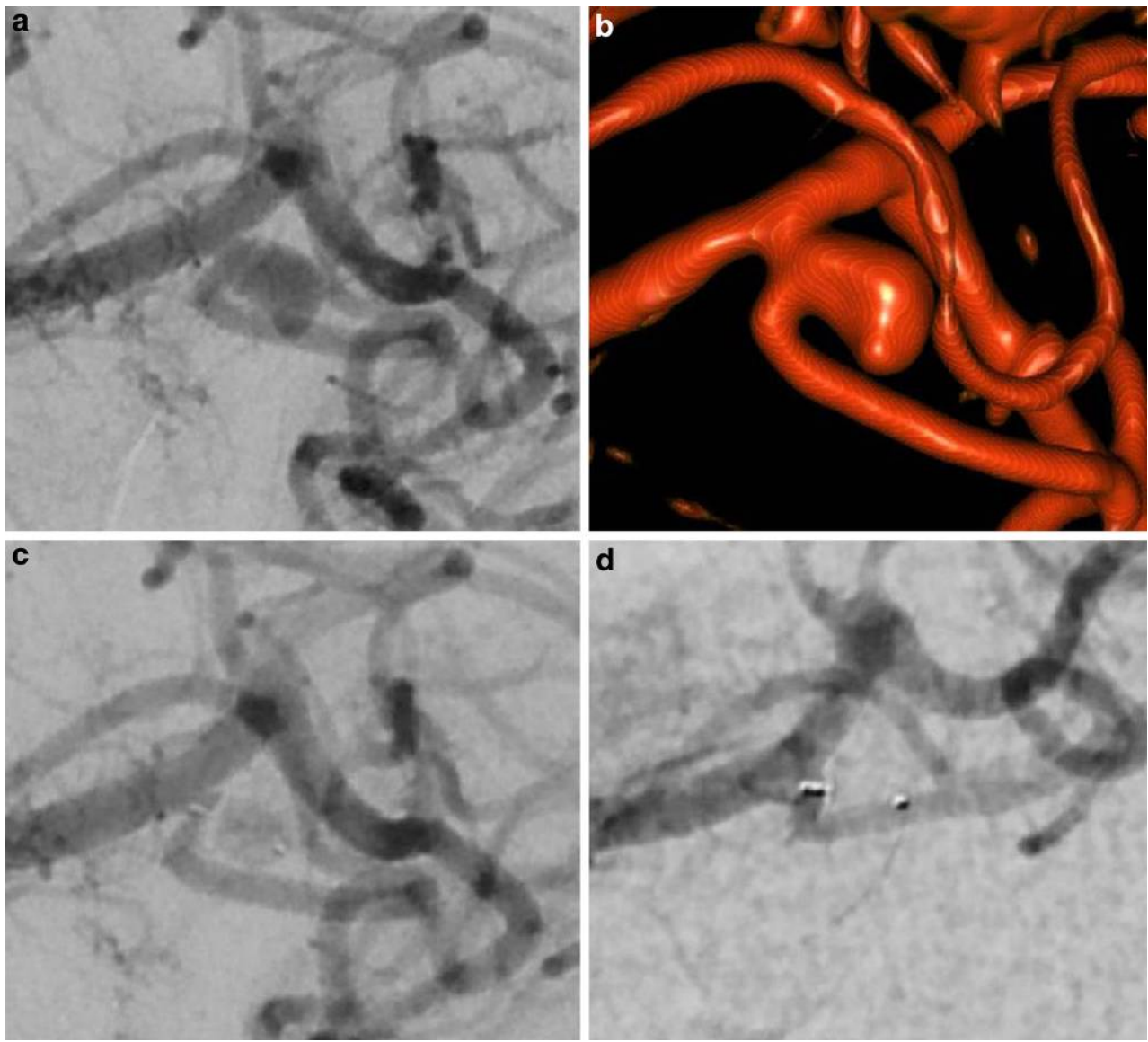
(12/21 aneurysms) for WEB 21 and 70.0\% (21/30) for WEB 17 treated aneurysms. The occlusion rates of the subgroup analysis are summarized in Table 4.

Fig. 1a-d illustrates the treatment of an unruptured MCA bifurcation aneurysm with a WEB 17 SL $4.5 \times 3 \mathrm{~mm}$ device including the 3 months follow-up angiography.

\section{Discussion}

The WEB device has been investigated in multiple prospective good clinical practice (GCP) studies, revealing complete and adequate occlusion rates that ranged from $52.8 \%$ to $53.9 \%$ and $79.0 \%$ to $84.6 \%$, respectively $[1-3,11,12]$. None of the studies included the WEB 17 system mainly because the studies were initiated before the introduction of WEB 17.

Complete occlusion rates achieved with WEB 17 ranged from $72.0 \%$ to $91.6 \%$ whereas these results were from single center self-reported series [7, 8, 13]. The CLEVER study that is currently ongoing at European centers investigates the WEB 17 in the treatment of ruptured and unruptured intracranial aneurysms and 10 of all the aneurysms in the WEB 17 group of our series were also included in CLEVER [14].

\section{Key Results}

Our analysis confirms the superiority of WEB 17 with an immediate and 3-month complete occlusion rate of $11.7 \%$ and $55.1 \%$ in the WEB 21 compared to 14.8 and $65.5 \%$ in the WEB 17 group, respectively. The results were statistically significant in the subgroup analysis of unruptured MCA aneurysms.

\section{Interpretation}

The most probable reason for the higher rate of complete occlusion in the WEB 17 group was likely due to the growing experience with the device, which results in a more appropriate amount of oversizing. Nevertheless, the higher occlusion rate in aneurysms treated with WEB 17 will at least in part be also related to the fact that these aneurysms are smaller in size within the adjusted subgroup since smaller aneurysms show a faster and more comprehensive thrombosis.

A comparison of the aneurysm locations within the two groups supports our hypothesis of an expansion of treatment indications with WEB 17 that is probably related to the smaller more flexible microcatheter needed for WEB 17 but again the learning curve might play an important role.

Goertz et al. in their analysis of intracranial aneurysms treated with WEB 17 compared with its previous versions observed no significant differences regarding the complete occlusion rate achieved with either device [15]. Contrary to our findings they had a lower rate of thromboembolic complications with WEB $17(5.3 \%)$ compared to the cases treated with previous versions $(14.3 \%)$. Their rate of additional adjunctive devices such as stents was lower in the group treated with WEB 17, a fact that the authors used to explain the lower rate of thromboembolic events in this group. The rate of adjunctive devices as stents was quite similar between the two groups in our study which may explain the smaller difference in the thromboembolic events rate. The rates of thromboembolic events found in our analysis were comparable to those of the above discussed studies [4, 16-18].

\section{Limitations of the study}

Our study has several limitations that are mainly based on its retrospective design.

While cases treated with WEB 21 are overrepresented in the beginning of the sample period, the same applies for WEB 17 cases at the end of the observational period. Therefore, the influence of growing experience over time might be underrepresented in our comparative analysis.

\section{Conclusion}

The WEB 17 system is at least as safe and effective as the WEB 21 system with significantly higher rates of complete occlusion for unruptured aneurysms of the MCA. The WEB 17 system offers the possibility to treat more distally located aneurysms compared to predecessor versions of WEB.

Funding This research received no specific grant from any funding agency in the public, commercial or not-for-profit sectors. For the 10 cases included in the CLEVER study funding was received according to the study protocol and money was paid to the institution.

Author Contribution I. König: project development, data collection, manuscript preparation, C. Maurer: project development, data collection, A. Berlis: data collection, critical review of the manuscript, V. Maus: critical review of the manuscript, W. Weber: critical review of the manuscript, S. Fischer: project development, data collection and analysis, manuscript preparation and writing

Conflict of interest C. Maurer: agreement with Microvention Inc./ Sequent Medical for consulting. A. Berlis: agreement with Microvention Inc./Sequent Medical for proctoring services and consulting. W. Weber: agreement with Microvention Inc./Sequent Medical for proctoring services and consulting. S. Fischer: agreement with $\mathrm{Mi}-$ crovention Inc./Sequent Medical for proctoring services and consulting. I. König and V. Maus declare that they have no competing interests. 


\section{References}

1. Arthur AS, Molyneux A, Coon AL, Saatci I, Szikora I, Baltacioglu F, Sultan A, Hoit D, Delgado Almandoz JE, Elijovich L, Cekirge S, Byrne JV, Fiorella D; WEB-IT Study investigators. The safety and effectiveness of the Woven EndoBridge (WEB) system for the treatment of wide-necked bifurcation aneurysms: final 12month results of the pivotal WEB Intrasaccular Therapy (WEB-IT) Study. J Neurointerv Surg. 2019;11:924-30.

2. Pierot L, Spelle L, Molyneux A, Byrne J; WEBCAST and French Observatory Investigators. Clinical and Anatomical Follow-up in Patients With Aneurysms Treated With the WEB Device: 1-Year Follow-up Report in the Cumulated Population of 2 Prospective, Multicenter Series (WEBCAST and French Observatory). Neurosurgery. 2016;78:133-41.

3. Pierot L, Costalat V, Moret J, Szikora I, Klisch J, Herbreteau D, Holtmannspötter M, Weber W, Januel AC, Liebig T, Sychra V, Strasilla C, Cognard C, Bonafé A, Molyneux A, Byrne JV, Spelle L. Safety and efficacy of aneurysm treatment with WEB: results of the WEBCAST study. J Neurosurg. 2016;124:1250-6.

4. Caroff J, Mihalea C, Klisch J, Strasilla C, Berlis A, Patankar T, Weber W, Behme D, Jacobsen EA, Liebig T, Prothmann S, Cognard C, Finkenzeller T, Moret J, Spelle L. Single-Layer WEBs: Intrasaccular Flow Disrupters for Aneurysm Treatment-Feasibility Results from a European Study. AJNR Am J Neuroradiol. 2015;36:1942-6.

5. Ding YH, Lewis DA, Kadinvel R, Dai D, Kallmes DF. The Woven EndoBridge: a new aneurysm occlusion device. AJNR Am J Neuroradiol. 2011;32:607-11.

6. Popielski J, Berlis A, Weber W, Fischer S. Two-center experience in the endovascular treatment of ruptured and unruptured intracranial aneurysms using the WEB Device: a retrospective analysis. AJNR Am J Neuroradiol. 2018;39:111-7.

7. Maurer C, König I, Berlis A, Weber W, Fischer S. Two-Center Experience in the Endovascular Treatment of Intracranial Aneurysms Using the Woven EndoBridge 17 Device Including Midterm Follow-Up Results: A Retrospective Analysis. AJNR Am J Neuroradiol. 2019;40:1517-22.

8. Van Rooij SBT, Peluso JP, Sluzewski M, Kortman HG, van Rooij WJ. The new low-profile WEB 17 system for treatment of intracranial aneurysms: first clinical experience. AJNR Am J Neuroradiol. 2018;39:859-63.

9. Lescher S, du Mesnil de Rochemont R, Berkefeld J. Woven Endobridge (WEB) device for endovascular treatment of complex unruptured aneurysms-a single center experience. Neuroradiology. 2016;58:383-90.
10. Roy D, Milot G, Raymond J. Endovascular treatment of unruptured aneurysms. Stroke. 2001;32:1998-2004.

11. Pierot L, Gubucz I, Buhk JH, Holtmannspötter M, Herbreteau D, Stockx L, Spelle L, Berkefeld J, Januel AC, Molyneux A, Byrne JV, Fiehler J, Szikora I, Barreau X. Safety and Efficacy of Aneurysm Treatment with the WEB: Results of the WEBCAST 2 Study. AJNR Am J Neuroradiol. 2017;38:1151-5.

12. Pierot L, Moret J, Barreau X, Szikora I, Herbreteau D, Turjman F, Holtmannspötter M, Januel AC, Costalat V, Fiehler J, Klisch J, Gauvrit JY, Weber W, Desal H, Velasco S, Liebig T, Stockx L, Berkefeld J, Molyneux A, Byrne J, Spelle L. Safety and efficacy of aneurysm treatment with WEB in the cumulative population of three prospective, multicenter series. J Neurointerv Surg. 2018;10:553-9.

13. Mihalea C, Caroff J, Pagiola I, Ikka L, Hashemi GB, Naderi S, Chalumeau V, Ples H, Popa BV, Yasuda T, Marenco de la Torre JJ, Iacobucci M, Ozanne A, Gallas S, Rouchaud A, Pescariu S, Moret J, Spelle L. Safety and efficiency of the fifth generation Woven EndoBridge device: technical note. J Neurointerv Surg. 2019;11:511-5.

14. CLEVER CLinical EValuation of WEB 0.017 Device in Intracranial Aneurysms. 2019. https://www.clinicaltrials.gov. Accessed 15 May 2020.

15. Goertz L, Liebig T, Siebert E, Herzberg M, Pennig L, Schlamann M, Borggrefe J, Krischek B, Dorn F, Kabbasch C. Low-Profile Intra-Aneurysmal Flow Disruptor WEB 17 versus WEB Predecessor Systems for Treatment of Small Intracranial Aneurysms: Comparative Analysis of Procedural Safety and Feasibility. AJNR Am J Neuroradiol. 2019;40:1766-72.

16. Goertz L, Liebig T, Siebert E, Herzberg M, Neuschmelting H, Borggrefe J, Onur ÖA, Dorn F, Kabbasch C. Risk Factors of Procedural Complications Related to Woven EndoBridge (WEB) Embolization of Intracranial Aneurysms. Clin Neuroradiol. 2020;30: 297-304.

17. Lawson A, Molyneux A, Sellar R, Lamin S, Thomas A, Gholkar A, Patankar T. Safety results from the treatment of 109 cerebral aneurysms using the Woven EndoBridge technique: preliminary results in the United Kingdom. J Neurosurg. 2018;128:144-53.

18. Fiorella D, Molyneux A, Coon A, Szikora I, Saatci I, Baltacioglu F, Sultan A, Arthur A; WEB-IT Study Investigators. Demographic, procedural and 30-day safety results from the WEB Intra-saccular Therapy Study (WEB-IT). J Neurointerv Surg. 2017;9:1191-6. 